\title{
Socioeconomic well-being of orphans and vulnerable children in orphanages within Cross River State, Nigeria
}

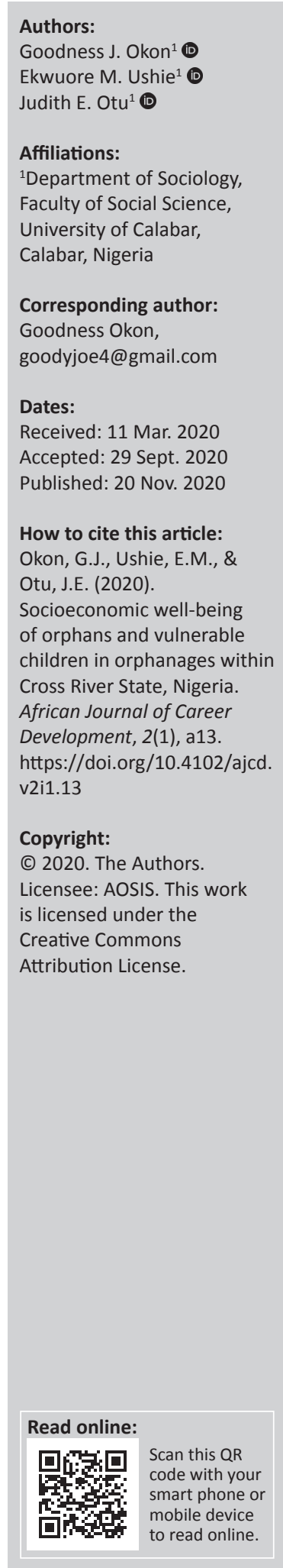

Background: The social and economic needs of a growing child are paramount to his or her entire well-being. As the number of orphans and vulnerable children in the country keep increasing, their socioeconomic challenges are also expanding. This research work investigated the socioeconomic well-being of orphans and vulnerable children (OVC) in two orphanages within Calabar South Local Government Area, Cross River State, Nigeria.

Objectives: Four objectives were highlighted to include unearthing the level of OVC school enrolment: school attendance, vocational training, educational challenges and possible solutions.

Method: The study adopted a descriptive research design and used simple random sampling technique to select respondents for the survey. A sample size of 64 was obtained using Taro Yamane's formula. The respondents comprised 26 males and 38 females, within the age range of 2-18 years. Instruments for primary data collection were structured questionnaire for the children and key informant interview for the caregivers. Data were analysed with Statistical Package for Social Sciences computer software and presented thematically, using simple percentages, frequencies, frequency polygon, bar chart and pie chart.

Results: The study revealed that a greater number of OVC were enrolled in school, more than average maintained regular school attendance, few children obtained vocational training and many experienced educational challenges.

Conclusion: It was recommended amongst others that the government should provide adequate educational materials to OVC in orphanages, vocational education should be considered as basic education for all children, and individuals and private or public organisations should also provide the OVC with basic support to ameliorate their educational challenges.

Keywords: school enrolment; school attendance; academic performance; orphans and vulnerable children; educational challenge; vocational training.

\section{Introduction}

There has been escalating rate of orphans and vulnerable children (OVC) since early 21st century. It was reported in 2008 that about 145 million children globally have lost at least one parent (WHO \& UNAID, 2008). In Nigeria, the Federal Ministry of Women Affairs and Social Development reported that Nigeria has approximately 17.5 million OVC (Federal Ministry of Women Affairs and Social Development, 2012). The United Nations Agency for International Development (UNAID) defines an orphan as a child, under 18 years of age, who has lost one or both parents. Those children experiencing unfavourable conditions such as malnutrition, morbidity, loss of education, chronic illness and disability are known as vulnerable children (The Joint United Nations Programme on HIV and AIDS [UNAIDS], 2011).

Socioeconomic indices such as education and career development are seen as basic human right for all children. These are catalyst for national development and also set foundation for individuals' productive and healthy living (UNESCO, 2019). A child who can access quality primary education has the basic foundation for continued learning in lifetime. Educational well-being in this context implies the school enrolment, attendance and performance of a child. Vocational training is such training that endows children with various skills so they can work as artisans, technicians or tradesmen. PEPFAR (2006) noted that schools not only benefit the children but can also serve as a powerful tool for meeting the developmental needs of the community. It is also observed that 
school attendance enables children who are traumatised to recover from psychosocial effect of their experiences and regain a sense of normalcy (USAID \& CRS, 2008). Miller (2019) assumed that vocational education prepares learners to be useful to themselves and their community by equipping them with both practical and manual skills. It is a training ground that gives people assurance concerning their lifetime career.

Orphans and vulnerable children encounter several challenges that impact negatively on their socioeconomic well-being. Studies conducted by CRS and CSN (2008) revealed that orphans have lower school attendance than non-orphans. Fleming (2015), who carried out a study on education for orphans or vulnerable children affected by human immunodeficiency virus (HIV), discovered that paternal orphans are less discriminated against in accessing education than maternal or double orphan. Orphans experience financial constraints and as such cannot afford the cost of education. The study conducted in Kenya by Subbarao, Maltimore and Plangemann (2010) disclosed some inhibiting factors to OVC's accessibility to quality education are lack of educational capacity, additional cost of education, low quality of education and inability to attend school on full time basis. In addition, Richter (2004) demonstrated that some orphans are deprived of their education in event of parental death, whilst some live in households with food insecurity.

Despite the execution of Free Primary Education Policy in Nigeria and donations made to orphanages by nongovernmental organisations (NGOs), individuals, private and public organisations, OVC are at higher risk of being dropped out of school. This poses short-term, medium-term and long-term socioeconomic threat to national development. Most OVC are seen hawking or playing on the streets during school hours. This study became necessary after a careful observation of alarming rate of street children in Calabar South Local Government Area. Some of these children were seen on uniforms still parading the streets instead of being in school.

Several studies have been carried out on the needs and psychosocial support given to OVC in Nigeria. However, no research work has been carried out on the assessment of educational well-being of OVC in Calabar South Local Government Area. Paucity of this knowledge has inhibited the development of adequate strategy to ameliorate educational challenges encountered by the OVC.

This study aimed at unearthing the socioeconomic situation of OVC in Calabar South Local Government Area, Cross River State, Nigeria. The study sought to answer the following research questions:

- What is the level of OVC's school enrolment in Calabar South Local Government Area?

- What is the level of OVC's school attendance in Calabar South Local Government Area?
- What is the academic performance of $\mathrm{OVC}^{\prime}$ in Calabar South Local Government Area?

- What is the height of OVC's vocational training in Calabar South Local Government Area?

- What are the educational challenges experienced by the OVC in Calabar South Local Government Area?

- What strategies can be used to mitigate these challenges?

\section{Conceptual framework Amartya Sen's capability approach}

The capability approach is associated with Amartya Sen, an Indian economist and a philosopher. It focuses on the capability of individuals to achieve the kind of lives they can value. 'Poverty' here is seen as a deprivation in individuals' capability to live a good life. In his capability approach, Sen (1999) argues that it is imperative whilst evaluating well-being to consider what people are really able to be and do. According to Sen, the well-being of people is about expansion of capabilities. His capability approach is concerned with expanding the real freedoms people enjoy. His core concepts are functioning, capabilities and agency. Those things people value being and doing are known as functioning; capabilities are the opportunities exposed to individuals and ability to achieve the desired results, whilst agency entails the interactive role played by individuals in the society, such as political, social and economic roles.

In Sen's perspective, 'poverty' which is seen as deprivation should be taken away from the OVC. Their capabilities should be developed to enable them access various opportunities and make choices. As observed by Hossain (2013), most OVC live in abject poverty, and consequently, they are dropped out of school because of their inability to pay fees and purchase educational materials, and they are also bereft of the vocational skills, which could provide them with manual jobs. This situation compromises the OVC's access to the necessary opportunities for improvement of their life chances. It, therefore, becomes necessary for possible interventions to emerge to reduce OVC's educational challenges because education provides a child with hope for work and life, and also serve as a strong protection against sexual abuse and exploitation. Through quality education, the capabilities of OVC can be expanded, exposing them to various alternatives they can choose from, thereby, enabling them to live valuable lives and also achieve their goals.

Sen's capability approach has been criticised for laying much emphasis on individuals' freedom without considering communal values and life patterns (Gore, 2007). It is also noted that Sen's concept of individuals' freedom is vague and cannot explain how a person's freedom affects others (Nussbaum, 2003). Notwithstanding, this approach is still very relevant to the understanding of people's well-being. 


\section{Methodology \\ Research design and study area}

This study adopted a descriptive research design. The choice of this design was based on the researcher's intention to analytically describe the educational and vocational situation of OVC in orphanages. It was conducted in two orphanages within Calabar South Local Government Area, namely Uwanse Motherless Babies Home and Infant Jesus Orphanage Home. Calabar is the capital of Cross River State, Southern Nigeria, and lies along the Calabar River and Cross River Delta. Calabar is divided into Calabar South and Calabar Municipal Local Government Areas with an area of 406 square kilometers and a population of 371022 at 2006 census.

\section{Respondents and setting}

The study population is made up of children within school age (2-18 years) living in the two orphanages. Uwanse Motherless Babies Home had 40 children and Infant Jesus Orphanage Home had 36 children, making it a total of 76 children. Simple random sampling technique was used to

TABLE 1: Socio demographic characteristics of respondents.

\begin{tabular}{|c|c|c|c|c|}
\hline S. no. & Statement & Option & Frequency & $\%$ \\
\hline \multirow[t]{4}{*}{1} & Age & $2-6$ years & 21 & 32.8 \\
\hline & & $7-11$ years & 10 & 15.6 \\
\hline & & $12-18$ years & 33 & 51.6 \\
\hline & & Total & 64 & 100.0 \\
\hline \multirow[t]{5}{*}{2} & Sex & Male & 26 & 40.6 \\
\hline & & Female & 38 & 59.4 \\
\hline & & Total & 64 & 100.0 \\
\hline & & Nursery & 18 & 28.1 \\
\hline & & Primary & 17 & 26.5 \\
\hline \multirow[t]{5}{*}{3} & Educational level & Secondary & 21 & 32.8 \\
\hline & & Tertiary & 4 & 6.3 \\
\hline & & None & 4 & 6.3 \\
\hline & & Total & 64 & 100.0 \\
\hline & & Living with disability & 5 & 7.8 \\
\hline \multirow[t]{4}{*}{4} & OVC status & Paternal orphan & 25 & 39.1 \\
\hline & & Maternal orphan & 8 & 12.5 \\
\hline & & Double orphan & 26 & 40.6 \\
\hline & & Total & 64 & 100.0 \\
\hline
\end{tabular}

OVC, orphans and vulnerable children.

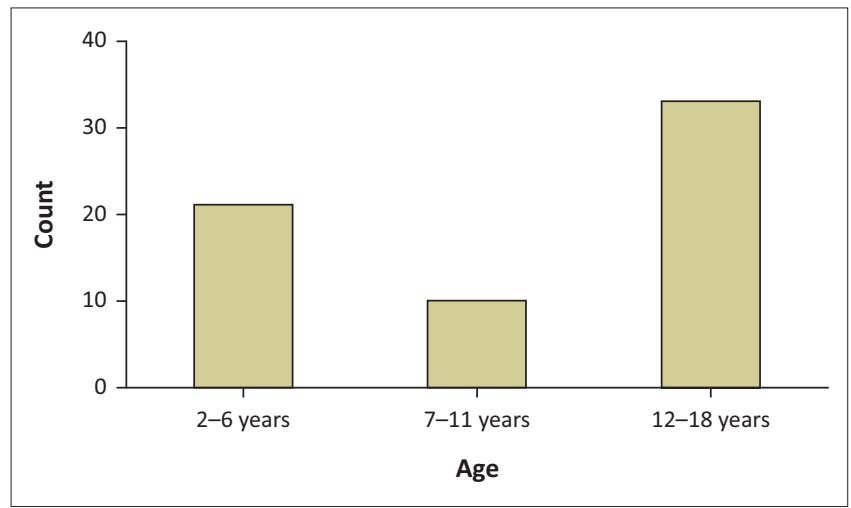

FIGURE 1: Distribution of respondents' responses on age. select respondents for the survey whilst the sample size of 64 was obtained using Taro Yamane's formula.

\section{Sociodemographic characteristics of respondents}

Table 1 and Figures 1-4 demonstrate the sociodemographic characteristics of respondents. As shown in Figure 1, $21(32.8 \%)$ respondents belonged to the age range of $2-6$ years, $10(15.6 \%)$ respondents belonged to the range of $7-11$ years and $33(51.6 \%)$ respondents belonged to the age range of 12-18 years. Distribution of respondents by sex reveals a greater number of female respondents $38(59.4 \%)$ as compared with male respondents 26 (40.6\%) (see Figure 2). Responses on educational level specify that 18 respondents representing $28.1 \%$ were in nursery schools, 17 respondents representing $26.5 \%$ were in primary schools, 21 respondents representing $32.8 \%$ attended secondary schools and four respondents representing $6.3 \%$ were in tertiary institutions whereas the remaining four respondents representing $6.3 \%$ were not in any school (see Figuer 3). Figure 4 indicates that five $(7.8 \%)$ respondents were living with disability, $25(39.1 \%)$ respondents were paternal orphans and eight

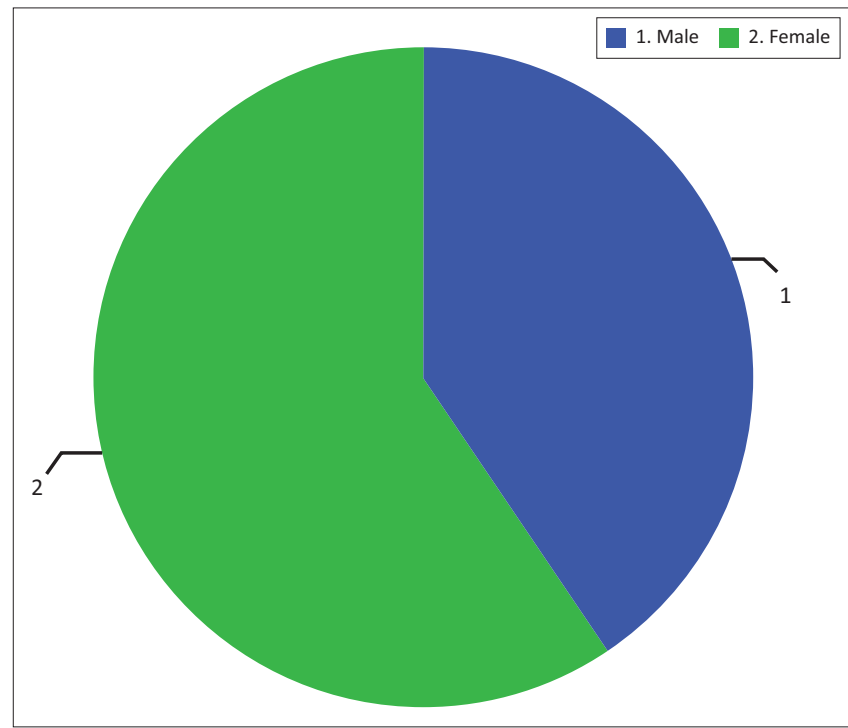

FIGURE 2: Distribution of respondents' responses on sex (female respondents 38 [59.4\%] as compared with male respondents 26 [40.6\%]).

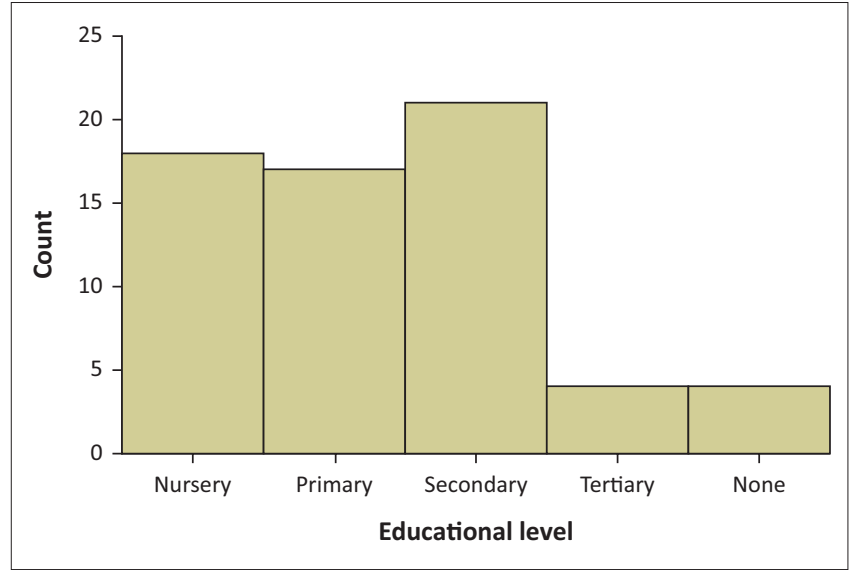

FIGURE 3: Distribution of respondents' responses on educational level. 


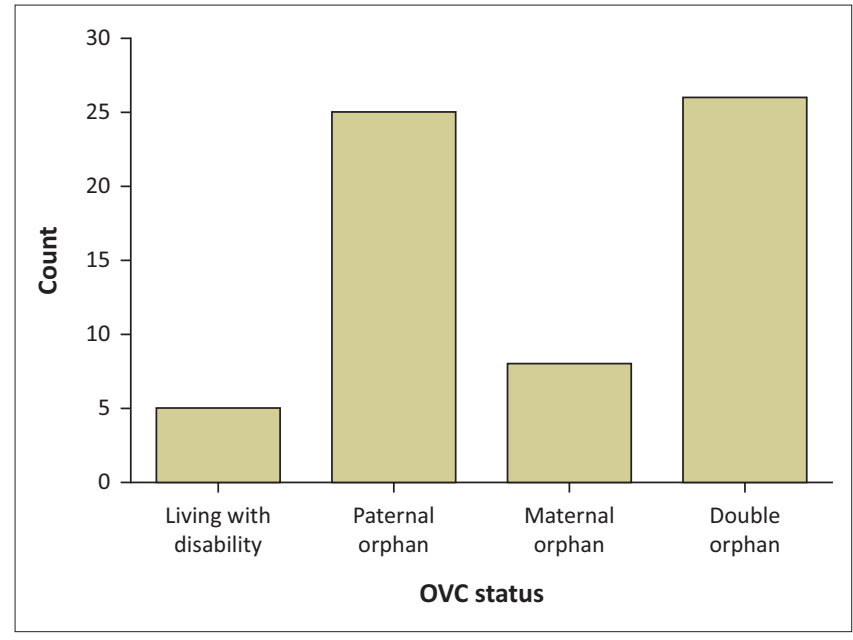

OVC, orphans and vulnerable children.

FIGURE 4: Distribution of respondents' responses on orphans and vulnerable children status.

(12.5\%) respondents were maternal orphans, whilst 26 (40.6\%) respondents were double orphans.

\section{Instrumentation}

Instruments used for data collection were structured questionnaire for the children and key informant interview (KII) for the caregivers. The caregivers assisted in filling questionnaire for children between 2 and 8 years old. The questionnaire was divided into two segments: the first segment was made up of sociodemographic characteristics of respondents, whilst the second segment was designed to divulge information on the study variables, such as school enrolment, school attendance, academic performance, vocational training and educational challenge. A nominal scale with 'Yes' or 'No' options was used to design the questionnaire. Whilst developing a coding key, 'Yes' option was assigned with a nominal value of 1 , and 'No' option was assigned with 2. Key informant interview schedule for caregivers was designed based on the five variables under study. The qualitative data obtained were tape-recorded to enhance proper analysis. The fieldwork was carried out with the help of two research assistants who guided the children in the process of filling questionnaire.

\section{Data analysis}

Quantitative data from questionnaires were coded and analysed through descriptive statistics (frequencies and percentages) using the Statistical Package for Social Sciences (SPSS) version 22.0; Qualitative data from the interviews were thematically analysed using a procedure by Braun and Clarke (2019).

\section{Ethical consideration}

Ethical approval to conduct the study was obtained from the Ministry of Health, Cross River State. The research team went through all the necessary criteria to fulfil ethical requirements such as obtaining ethical clearance from the
TABLE 2: Distribution of respondents' responses on school enrolment, attendance and performance.

\begin{tabular}{lllcc}
\hline S. no. & Statement & Option & Frequency & \% \\
\hline 1 & Are you enrolled & Yes & 60 & 93.8 \\
& in school? & No & 4 & 6.2 \\
& & Total & 64 & 100.0 \\
2 & How many days do & 5 days & 40 & 62.4 \\
& $\begin{array}{l}\text { you attend school } \\
\text { in a week? }\end{array}$ & 4 days & 4 & 6.3 \\
& & 3 days & 4 & 6.3 \\
& & 2 days & 12 & 18.7 \\
& & None & 4 & 6.3 \\
& & Total & 64 & 100.0 \\
& & Very good & 14 & 21.8 \\
& & Good & 34 & 53.1 \\
& & Fair & 9 & 14.1 \\
& What was your academic & performance in the last \\
examinations? & Poor & 3 & 4.7 \\
& & Nil & 4 & 6.3 \\
& & Total & 64 & 100.0 \\
\hline
\end{tabular}

Ministry of Health Ethical Committee, seeking informed consent of the respondents, ensuring voluntary participation and anonymity.

\section{Results}

\section{Participants' responses on school enrolment, school attendance and academic performance}

Table 2 shows the distribution of respondents' responses on school enrolment, attendance and performance. Responses on 'Are you enrolled in school?' point out that 60 (93.8\%) respondents maintained being enrolled in school, whilst only four $(6.3 \%)$ respondents were of negative response. On the question 'How many days do you attend school in a week?', more respondents $40(62.4 \%)$ claimed attending school for all the 5 days in a week, four $(6.3 \%)$ respondents attended 4 days in a week, another four (6.3\%) respondents attended 3 days in a week and $12(18.7 \%)$ respondents attended 2 days in a week, whereas the remaining four (6.3\%) respondents had not been to school. Responses on 'What was your academic performance in the last examinations?' revealed that 14 respondents representing 21.8\% reported having a very good performance, 34 respondents representing $53.1 \%$ maintained having good performance, nine respondents representing $14.1 \%$ reported fair performance and three respondents representing $4.7 \%$ maintained poor performance. A total of four $(6.3 \%)$ respondents were those who had no school enrolment.

\section{Participants' responses on vocational training}

Table 3 describes the distribution of respondents' responses on vocational training obtained. As displayed in the table, 27 respondents representing 42.2\% reported obtaining vocational training, whilst $37(57.8 \%)$ respondents had no such training. On the question 'What type of vocational training have you obtained?', two (3.1\%) respondents learned carpentry, three $(4.7 \%)$ learned hairdressing, five $(7.8 \%)$ tailoring, another five $(7.8 \%)$ artwork, three $(4.7 \%)$ masonry, five $(7.8 \%)$ practical nursing and four $(6.3 \%)$ respondents learned other skills, which were not listed by the researcher. 
TABLE 3: Distribution of respondents' responses on vocational training.

\begin{tabular}{lllcc}
\hline S. no. & Statement & Option & Frequency & $\mathbf{\%}$ \\
\hline 1 & Have you obtained any & Yes & 27 & 42.2 \\
& vocational training? & No & 37 & 57.8 \\
& & Total & 64 & 100.0 \\
& & Carpentry & 2 & 3.1 \\
2 & What type of vocational & Hairdressing & 3 & 4.7 \\
& training have you & Tailoring & 5 & 7.8 \\
& obtained? & Artwork & 5 & 7.8 \\
& & Masonry & 3 & 4.7 \\
& & Practical nursing & 5 & 7.8 \\
& & Others & 4 & 6.3 \\
& & None & 37 & 57.8 \\
& & Total & 64 & 100.0 \\
\hline
\end{tabular}

TABLE 4: Distribution of respondents' responses on educational challenge.

\begin{tabular}{|c|c|c|c|c|}
\hline S. no. & Statement & Option & Frequency & $\%$ \\
\hline \multirow[t]{4}{*}{1} & \multirow{4}{*}{$\begin{array}{l}\text { Have you } \\
\text { encountered } \\
\text { any educational } \\
\text { challenge? }\end{array}$} & Yes & 47 & 73.4 \\
\hline & & No & 17 & 26.6 \\
\hline & & Total & 64 & 100.0 \\
\hline & & Non-payment of school fees & 5 & 7.8 \\
\hline \multirow[t]{6}{*}{2} & \multirow{6}{*}{$\begin{array}{l}\text { What is the } \\
\text { nature of } \\
\text { educational } \\
\text { challenge? }\end{array}$} & Lack of educational materials & 33 & 51.5 \\
\hline & & Lack of food & 4 & 6.3 \\
\hline & & Illness & 4 & 6.3 \\
\hline & & Neglect & 1 & 1.6 \\
\hline & & None & 17 & 26.5 \\
\hline & & Total & 64 & 100.0 \\
\hline
\end{tabular}

\section{Participants' responses on educational challenge}

Table 4 illustrates respondents' responses on educational challenge experienced. On the question 'Have you encountered any educational challenge?' A total of 47(73.4\%) respondents reported going through educational challenge, whilst $17(26.6 \%)$ respondents reported not having any challenge. On 'What is the nature of educational challenge?', it can be observed in Table 4 that out of the 64 respondents, five representing $7.8 \%$ reported non-payment of school fees as their educational challenge, 33 respondents representing $51.5 \%$ reported lack of educational materials, four respondents representing 6.3\% reported hunger as their challenge, another four respondents representing $6.3 \%$ reported illness as their challenge and one (1.6\%) respondent reported emotional abuse, whereas 17 respondents representing $26.5 \%$ reported no educational challenge.

\section{Data from key informant's interview}

Two senior caregivers were interviewed in the two orphanages, one from each orphanage; the results are presented below, according to the major themes in the study.

\section{Orphans and vulnerable children's school enrolment}

The study participants reported that the OVC within school age were all registered in school, except those with disabilities. Below are statements from the interviewees:

'All the children within school age have been enrolled except those with disability, we need more support to enable us send them to a school which takes care of children with disabilities.' (Key informant \#1, female, 49 years old, Orphanage 1)

'They are all registered in school, only those ones who cannot talk are yet to be registered.' (Key informant \#2, female, 53 years old, Orphanage 2)

\section{Orphans and vulnerable children's school attendance}

The interviewees generally reported that the OVC attend school on regular basis. Illustrative statements from the participants are given below:

'They all attend school on regular basis, some are boarders, and they just came back because of mid-term break.' (Key informant \#1, female, 49 years old, Orphanage 1)

'They attend school regularly except when they are ill or have some minor challenges. Although there are some who don't like going to school on daily basis, we do our best to make sure they attend school.' (Key informant \#2, female, 53 years old, Orphanage 2)

\section{Orphans and vulnerable children's academic performance}

Some of the OVC brought their examination results that were used to rate their performance; a greater number of the children had excellent performance. Also, the interviewees reported that most OVC's academic performance were good. Illustrative statements from the caregivers are given below:

'Most of these children are very brilliant; two of them who performed excellently got admission into the University of Calabar.' (Key informant \#1, female, 49 years old, Orphanage 1).

'Some of them are very good academically; others are still coming up.' (Key informant \#2, female, 53 years old, Orphanage 2).

\section{Vocational training}

The participants reported that those children who were of age to learn skills were trained, but their major problem was the inability to establish these children after vocational trainings. Below are statements from the participants:

'It is only the older ones that are allowed to learn handwork, mostly when they are on long-break; these skills can help them to earn income even without 'white-collar job.' (Key informant \#1, female, 49 years old, Orphanage 1).

'Some of them have learnt vocational skills, but there is no money to buy the necessary equipments or machines for them, only few have been established after vocational training.' (Key informant \#2, female, 53 years old, Orphanage 2).

\section{Educational challenge}

The participants reported insufficient educational materials as the OVC's major educational challenge. The interviewees' illustrative statements are given below:

'Though the church takes care of their school fees, we need supports to enable us provide the necessary educational materials to them.' (Key informant \#1, female, 49 years old, Orphanage 1) 
'Some well-minded individuals, organizations, and the government do take care of their school fees. Yet there are some serious educational demands that must be addressed such as uniforms, shoes, books, etc.' (Key informant \#2, female, 53 years old, Orphanage 2)

\section{Discussion}

From the given results, it can be deduced that a greater number of OVC in orphanages are enrolled in various schools ranging from nursery to higher institution. Only four out of 64 children were not enrolled in school and these four children were either disable or sick. This finding is contrary to the erroneous belief that OVC in orphanages lack educational background. The study lends credence to the work of Mutiso and Mutie (2018) who studied the challenges affecting OVC in Embu County and found that $74.9 \%$ of orphans were schooling, whereas $21.1 \%$ were not schooling. It is further supported by the work of Okon and Ojua (2018) on psychosocial support and well-being for OVC as a strategy for poverty reduction in Cross River and Ebonyi States. This study revealed the percentage of OVC enrolled in school within Cross River and Ebonyi States to be $89.2 \%$ and $76 \%$, respectively.

As it relates to school attendance, majority of the children attended school regularly. Only 31.3\% maintained irregular school attendance. As explained by the caregivers, such irregular attendance is because of educational challenges experienced by the children. In consonance with this finding, Olanrewaju, Jeffery, Crossland and Valadez (2015), who carried out a study on access to education for OVC in Uganda, observed that $79.1 \%$ of OVC attended school within 3-year period. This particular result contradicts the finding of Okon and Ojua (2018) who maintained the percentage of OVC with regular school attendance to be a little above average (56.8\%) in Cross River State and less than average (39.9\%) in Ebonyi State.

With regard to the children's academic performance, a lesser number of the OVC (18.8\%) did not perform well, whereas a greater part of them $(74.9 \%)$ had better performance. This demonstrates that most OVC in orphanages perform well academically. To buttress this point, Okon and Ojua (2018) exposed in their work that $58.6 \%$ and $66.7 \%$ of the children aged 0-9 years progressed in school over time, in Cross River and Ebonyi States, respectively, whilst $83.3 \%$ and $66.7 \%$ of children aged $10-17$ years progressed in school correspondingly in Cross River and Ebonyi States. This finding contradicts the outcome of the study carried out by Pillay and Nesengani (2006) on educational challenges facing OVC. Their study found that most OVC experienced poor academic performance because of the inability to complete their school tasks and poor academic performance.

With reference to vocational training, only 27 respondents representing $42.2 \%$ reported learning some vocational skills. This set of respondents belonged to the 12-18 age group, as confirmed by United Nations Children's Fund (UNICEF, 2009), which positioned that $90 \%$ of the beneficiaries of
Community Harnessed Initiatives for Children's Learning and Development (CHILD) programme in Rwanda were OVC between 15 years old and above. The 27 respondents learnt skills such as carpentry, hairdressing, tailoring, masonry, nursing, arts and others. This finding agrees with that of Benjamin (2015) on 'Provision of vocational skills education to orphans'; his study revealed that $21(52.5 \%)$ OVC learnt tailoring, nine $(22.5 \%)$ computer, one $(2.5 \%)$ welding, four $(10.0 \%)$ driving, one $(2.5 \%)$ arts, three $(7.5 \%)$ carpentry and one $(2.5 \%)$ gardening. Most of the OVC who were school dropped out had another chance of improving their lives through these skills acquisition trainings.

In terms of educational challenges, Table 2 reveals that more children $(73.4 \%)$ experienced educational challenges. Few of them experienced non-payment of school fees, whilst a greater part lacked basic educational materials. As explained by the caregivers, some of these challenges include inability to meet daily school (financial) demands, buy books, uniforms, shoes, etc. It was observed by Mwoma and Pillay (2016) in a work titled 'Educational support for OVC in primary schools: Challenges and interventions', that factors such as low selfesteem, hunger, lack of concentration amongst OVC, absenteeism or lateness to school and poor hygiene are the challenges, which can have a negative impact on OVC academic performance. Pillay (2012) noted that most OVC find it difficult to read or do their homework when it gets dark because of poor power supply and inability to acquire alternatives. This situation has an adverse effect on the children's academic achievement.

\section{Implications for research and practice}

The socioeconomic well-being of OVC is a topical issue that necessitates a lot of research; the results of this study, therefore, add to the existing literature on this topic and as such expand knowledge. Practically, this study unearths the educational and vocational situation of OVC in orphanages. This will send alarming signal to the government organisations and NGOs and the general public on OVC educational and vocational challenges, thereby opening more doors for vocational and educational support. Moreover, the recommendations of this study, when implemented, will contribute to the formulation and implementation of policies, which will improve the socioeconomic well-being of OVC in Nigeria.

\section{Study limitations}

Few respondents' academic report sheets/booklets were not accessible at the time of carrying out this study. Also, it was difficult to obtain full concentration from the children whilst filling research questionnaire, as such the process was not void of mistakes. Those children living with disability could not report accurately. It is also worthy to state that the response from KII may not be completely free from bias because of the fact that the two key informants were caregivers and are bound to project a good image of the organisations (orphanages) they belong to. 


\section{Conclusion and recommendations}

Most OVC in orphanages are enrolled in school and also maintain regular school attendance. This could be because of the close monitoring and guidance of their caregivers. A small number of the children obtained vocational training. The respondents maintained high and encouraging academic performance, although very few had poor performance in school. According to the caregivers, this poor performance is attributed to educational challenges experienced by the children in terms of lack of funds to acquire the necessary educational materials and also offer other school-related provisions. The study, therefore, recommends that:

- The government should provide adequate educational materials to OVC in orphanages.

- Individuals, private and public organisations should help in providing the basic support to OVC in order to ameliorate their educational challenges.

- Non-governmental organisations, as well as the government should create a conducive environment with frequent power supply for the OVC in orphanages.

- Orphans and vulnerable children living with disability should be assisted by both private and public individuals / organisations to be enrolled in school of the disability children as well as monitor and encourage their sustained school attendance.

- Vocational education should be seen and treated as basic education for all children, especially the OVC, who may not have the opportunity to go higher in academics.

\section{Acknowledgements}

The authors would like to thank Reverend Joseph Okon Ibok for financial, moral, spiritual and physical support; Assoc. Prof. Agba for moral and academic support; and Dr E. Etobe for moral, spiritual and academic support.

\section{Competing interests}

The authors have declared that no competing interests exist.

\section{Authors' contributions}

The corresponding author did the whole work through the guidance of other authors.

\section{Funding information}

The research received no specific grant from any funding agency in the public, commercial or not-for-profit sectors.

\section{Data availability statement}

The authors confirm that the data supporting the findings of this study are available within the article.

\section{Disclaimer}

The views and opinions expressed in this article are those of the authors and do not necessarily reflect the official policy or position of any affiliated agency of the authors.

\section{References}

Benjamin, M.M. (2015). Provision of vocational skills education to orphans: Lessons from orphanage centres in Dar es Sallam City, Tanzania. Journal of Education and Practice, 6(15), 65-75.

Braun, V., \& Clarke, V. (2019). Reflecting on reflexive thematic analysis. Qualitative Research in Sport, Exercise and Health, 11(4), 589-597.

CRS and CSN. (2008). A situational analysis of orphans and vulnerable children in eight states of Nigeria. Retrieved from http://www.CRS.org/ovcsituationalanalysis-2. pdf

Federal Ministry of Women's Affairs and Social Development. (2012). Key findings situational assessment and analysis on OVC in Nigeria. Abuja: Federal Ministry of Women's Affairs and Social Development.

Fleming, K.E. (2015). Improving access to education for orphans or vulnerable children affected by HIV/AIDS. Retrieved from http://unesdoc.unesco.org/images/0023/ 002324/232423e.pd

Gore, C. (2007). Irreducibly social goods and the informational basis of Amartya Sen's capability approach. Journal of International Development, 9(2), 235-250. https://doi.org/10.1002/(SICI)1099-1328(199703)9:2\%3C235::AID-JID436\% 3E3.0.CO;2-J

Hossain, D. (2013). Ensuring food and nutrition security for orphan and vulnerable children. Durban: United Nations Children's Fund.

Miller, S. (2019). Why is vocational training necessary? Retrieved from https://www. vocational-training-necessary/

Mutiso, D.N., \& Mutie, P.M. (2018). Challenges affecting orphans and vulnerable children (OVC) in Embu County. International Journal of Sociology, 1(1), 18-36.

Mwoma, T., \& Pillay, J. (2016). Educational support for orphans and vulnerable children in primary schools: Challenges and interventions. Issues in Educational Research, 26(1), 82. https://doi.org/10.15700/saje.v35n3a1092

Nussbaum, M. (2003). Fundamental entitlements: Sen and social justice. Feminist Economics, 9(2), 33. https://doi.org/10.1080/1354570022000077926

Okon, I., \& Ojua, T. (2018). Psychosocial support and wellbeing for orphans and vulnerable children as a strategy for poverty reduction in Cross River and Ebonyi States, Southern Nigeria. International Journal of Research and Innovation in Social Science (IJRISS), 2(5), 197-204. https://doi.org/10.46281/aijssr.v2i1.169

Olanrewaju, A., \& Jeffery, C., Crossland N., \& Valadez J.J. (2015). Access to education for orphans and vulnerable children in Uganda: A multi-district, cross-sectional study using lot quality assurance sampling from 2011 to 2013. PLOS ONE 10(7):e0132905. https://doi.org/10.1371/journal.pone.0132905.

President's Emergency Plan for AIDS Relief (PEPFAR). (2006). Orphans and vulnerable children programming guidance. Retrieved from http://www.pepfar.gov/reports/ guidance/78161.htm

Pillay, J. (2012). Experiences of learners from child-headed households in a vulnerable school that makes a difference: Lessons for school psychologists. School Psychology International, 33(1), 3-21. https://doi.org/10.1177/0143034311409994

Pillay, J., \& Nesengani, R.I. (2006). The educational challenges facing early adolescents who head families in rural Limpopo province. Education as Change, 10(2), 131-147. https://doi.org/10.1080/16823200609487144

Richter, L. (2004). The impact of HIV/AIDS on the development of children. In C. Levine (Ed.), A generation at risk (pp. 9-31), Cambridge: Cambridge University Press.

Sen, A. (1999). Development as freedom. New York, NY: Oxford University Press.

Subbarao, K., Mattimore, A., \& Plangemann, K., 2010, 'Social protection of Africa's orphans and other vulnerable children: Issues and good practice programme options', Human Development working papaer series, African region, World Bank, Washington D.C.

The Joint United Nations Programme on HIV and AIDS (UNAIDS), 2011, UNAIDS terminology guidelines. viewed 12 May 2019, from https://files.unaids.org/en/ media/unaids/contentassets/documents/unaidspublication/2011/JC2118 terminology-guidelines_en.pdf

The United Nations Educational, Scientific and Cultural Organization (UNESCO) (2019). Education for health and wellbeing. Retrieved from https://en.unesco. org/themes/education-health-and-well-being

United Nations Children's Fund (UNICEF). (2009). Promoting quality education for orphans and vulnerable children. A sourcebook of programme experiences in Eastern and Southern Africa. New York, NY: United Nations Children's Fund.

United States Agency for International Development (USAID) \& CRS (Catholic Relief Services). (2008). Education programming for orphans and vulnerable children affected by or vulnerable to HIV: Moving beyond school fees and uniforms. Retrieved from http://pdf.usaid.gov/pdf-docs/pnadp105.pdf

World Health Organization (WHO) \& United Nations Agency for International Development (UNAID). (2008). Children and aids: Third stocktaking report. New York, NY: United Nations Children Fund. 